\title{
New Technologies and Techniques in Gastrointestinal Endoscopy
}

\author{
Eduardo Guimarães Hourneaux de Moura* and Caio Tranquillini \\ Endoscopy Unit, Hospital das Clínicas, University of São Paulo School of Medicine, USA
}

*Corresponding author: Eduardo Guimarães Hourneaux de Moura, Endoscopy Unit, Hospital das Clínicas, University of São Paulo School of Medicine, USA

Submission:

\begin{abstract}
Gastrointestinal endoscopy is an ever improving field. It is essential to the endoscopist to keep up-to-dated to the new technologies. In this article, we will discuss about the recent diagnostic and therapeutic enhancements of upper and lower endoscopy, their current indications and compare to the standard procedures that are available for endoscopic practice.
\end{abstract}

\section{Introduction}

Endoscopy is a growing area in medicine and new technologies and techniques arise constantly. In this review we summarize recent advances in diagnosis and therapy for gastrointestinal endoscopy. Endoscopy is the gold standard for diagnosis of gastrointestinal (GI) cancers, which are the most commonly diagnosed cancers worldwide and the second leading cause of cancer-related death $[1,2]$. Therefore, early identification of precancerous or early stage GI tumors is fundamental.

\section{Image enhancement innovations}

As processing image technologies advances with better image resolutions, new methods for diagnosis of early precancerous lesions are developed. Kudo et al. [3] described a chromo endoscopy dye-based method which increased the detection of these lesions. Following his innovation, new technologies, such as digital chromo endoscopy were developed to improve the detection rates and to reduce procedure time. The most common digital chromoscopy are: narrow-band imaging (NBI), flexible spectral imaging color enhancement (FICE) and I-Scan.

\section{Narrow-Band Imaging (NBI)}

NBI technology was developed by Olympus (Tokyo, Japan). It consists in the assessment of surface patterns and micro vascular architecture by using a narrowed spectrum light. Optical filters eliminate the red light and select blue and green wavelengths [4]. These lights are better absorbed by hemoglobin and penetrate the superficial mucosa structures providing an enhancement of mucosal features and blood vessels (capillaries from superficial mucosal layer, deeper mucosal and sub mucosal vessels) $[5,6]$.
The detection of irregular mucosal, vascular patterns and abnormal blood vessels (disappearance of fine mucosal structure, micro vascular dilation and heterogeneity in shape of vessels) had a $94 \%$ sensitivity and $76 \%$ specificity for detection of high-grade BE and a sensitivity of $92.9 \%$ and $94.7 \%$ specificity for the diagnosis of early gastric and esophageal cancer [7-10]. Moreover, NBI ability to predict colonic polyp's histology has been reported [11-13]. Endoscopists using Kudo's classification system of pit patternor NBI International Colorectal Endoscopic (NICE) classification can infer a polyp histology and adopt a better therapeutic strategy $[3,14]$.

\section{Flexible Spectral Imaging Color Enhancement (FICE)}

FICE technology was developed by Fujinon (Saitama, Japan). It changes the color of endoscopic images in real time based on software system. Unlike NBI, which utilizes physical optical light filters, FICE selects particular wavelengths from digitized data. The software arithmetically processes a regular endoscopic image from the video and produces an image with a dedicated wavelength of light. It reveals better mucosa details and clearer images by manipulating absorption and emission properties of light. FICE is better than conventional endoscopy to reveal capillary patterns of adenomas $[15,16]$ and therefore, it can determine whether an adenoma is neoplastic or non-neoplastic [17].

\section{I-Scan}

I-Scan technology was developed by Pentax Inc. (Tokyo, Japan). It is a type of virtual chromo endoscopy and is based on digital post-processing image. I-scan consists of three different image 
algorithms: surface enhancement (SE); tone enhancement (TE); and contrast enhancement (CE) [18]. Switching from each mode maximize the efficacy of imaging. The SE shows the mucosal by detailing small glands and lesion limits. The CE displays images obtained using blue light similar to NBI and reveals the superficial and vascular patterns of the studied area. TE improves identification of tiny mucosal structures and subtle changes in color $[18,19]$.

Therefore, three I-scan settings are possible: I-scan 1 for detection of lesions; I-scan 2 was established for characterization of lesions; I-scan 3 is recommended for demarcation of lesions $[18,20]$. When comparing I-Scan with conventional colonoscopy, the rate of detection of neoplastic lesions identified by conventional colonoscopy was $13 \%$, whereas by I-Scan the number raises to $38 \%$ [21]. The I-SCAN was used to differentiate neoplasias and nonneoplasias with a sensitivity of $98.6 \%$ [19].

\section{Confocal Laser Endomicroscopy}

The confocal laser endomicroscopy (CLE) is a technique which uses laser rather than white light as light source. It allows a meticulous examination of the mucosa by placing an endomicroscope at the end of the endoscope. There are two devices available for endomicroscopy:

\section{Pentax CLE (Pentax [Japan] and Opti-scan [Australia])}

A miniaturized endomicroscope is placed on the end of a standard 12.8-mm diameter endoscope and has a working channel with a diameter of $2.8 \mathrm{~mm}$. Using a blue laser beam this system enables acquisition of cross-sectional optical images with a $500 \mathrm{X}$ $500-\mu \mathrm{m}$ field of view, a $7-\mu \mathrm{m}$ resolution, and a $250-\mu \mathrm{m}$ depth from the mucosal surface [20].

\section{Cellvizio Probe-Based CLE (Mauna Kea, Paris, France)}

The Cellvizio system uses probes that are passed through the flexible working channel of the endoscope. It has different diameter sizes and can also be used in the bile and pancreatic duct due to its small size. However, it can only be used up to 20 times, which increases the overall cost. Moreover, as it is passed through the working channel, it is impossible to perform biopsies simultaneously in single channel endoscopes. The use of a dualchannel endoscope for CLE overcomes these restrictions [21]. Both CLE devices have long learning curves, need for dyes and a higher cost.

\section{Therapeutics Advances}

\section{Over-the-scope clip}

Over-the-scope Clip (OTSC) (OvescoEndoscopyAG, Tübingen, Germany) was primarily developed for endoscopic closure of perforations and fistulas. This technique it has been shown an $86 \%$ clinical success for resolution of GI fistulas [22]. More recently, OTSC has been used for endoscopic hemostasis with good results for peptic ulcers, Mallory-Weiss tears, and anastomotic bleeding [23]. The Food and Drug Administration (FDA) approved the following hemostatic indications for OTSC: bleeding ulcers, arteries
$<2 \mathrm{~mm}$, colon diverticula, polyps $<1.5 \mathrm{~cm}$ in diameter, and mucosal/ submucosal defects $<3 \mathrm{~cm}[24]$.

There are case reports in literature describing the use of OTSC to prevent the migration of fully covered self-expanding metal stents (SEMs) in GI pathologies [25].

\section{Radiofrequency ablation}

Radiofrequency ablation (RFA) with the HALO ablation system (Covidien, GI Solutions, Sunnyvale, CA) is already well established for the treatment of Barrett's esophagus. RFA is also been used to treat gastric antral vascular ectasia (GAVE) and, to prolong ductal patency in patients with malignant biliary strictures [26,27].

For Barrett's esophagus its main indication is when high-grade dysplasia is present. Although, Phoa et al. [28] demonstrated that the treatment for Barrett's esophagus with low-grade dysplasia may be cost-effective. Another trial showed that the combined therapy of endoscopic mucosal resection of high-grade dysplasia or early esophageal cancer areas followed by RFA is also effective [29].

For GAVE, RFA achieved complete response in $86 \%$ of patients in a 6-months follow-up trial [30]. Additionally, another study assessed that $87 \%$ of patients treated by this system did not require further transfusions in a 2 months follow-up [31]. Wang et al. [26] identified significant increase in bile duct diameter after RFA and biliary stenting. Kallis et al. [32] saw an increase in survival of patients with un resettable pancreatic cancer when biliary strictures were treated with RFA.

\section{Hemostatic powder}

The Hemospray ${ }^{\circledR}$ (Cook Medical TC-325) is a new endoscopic accessory and consists of a mineral powder that absorbs water when applied to an actively bleeding lesion, forming a mechanical barrier over the bleeding site [33]. This hemostatic powder has shown great outcomes in the context of upper gastrointestinal with a high rate of immediate hemostasis (96.5\%) [34]. There are reports of successful treatments of many different bleeding sources such as: portal hypertension, varices, tumors, iatrogenic and postESD.

\section{lumen-apposing metal stents}

Pancreatic fluid collections (PFCs) are, usually, asymptomatic and do not require any intervention. However, symptomatic or complicated PFCs demand treatment. Endoscopic drainage has excellent success rates, lower overall cost and shorter length of stay $[35,36]$.

Generally, typical plastic stents (double pig-tail) are deployed to drain these collections but fully-covered self-expanding metallic stents (FCSEMS) have also been used, especially for acute necrotic collections (ANCs) and walled-off necrosis (WON). The major drawback of the FCSEMS is the high migration rate. A new metallic stent with two large flanges and a larger lumen was recently developed to reduce this rate: the lumen-apposing metal stents (LAMS) [37]. 
Multiple LAMS are available worldwide including the NAGI and SPAXUS stents (Taewoong Medical, Gyeonggido, South Korea) and Axios (Boston Scientific, Marlborough, MA), which is approved by the FDA and the CE (Conformité Européene). Walter et al. [38] performed a multicenter prospective study with LAMS enrolling 61 patients with pancreatic pseudo cyst (PP) or WON. Technical success was achieved in $93 \%$ of patients in the PP group and in $81 \%$ of the patients in the WON group. Adverse events occurred in $9 \%$ of cases. There was a detachment of the stent in three cases during debridement and three spontaneous migrations of the LAMS. Following the success of LAMS when used for the drainage of PFCs, new trials are being performed to assess other drainage indications. One of these is direct endoscopic gallbladder drainage (GBD). Such procedure would be indicated for patients with acute or chronic cholecystitis, but poor candidates to surgery. LAMS is as effective and safe as percutaneous cholecystostomy drainage $[39,40]$.

\section{Conclusion}

New technologies and procedural advances for endoscopy improved the prognosis for GI affections. The early diagnosis of gastrointestinal neoplasias and the development of new techniques reduced morbimortality of endoscopic treatments. Enhancements of these technologies and further innovations will contribute to expand the indications of endoscopy and improve endoscopical outcomes.

\section{References}

1. Siegel R, Ma J, Zou Z, Jemal A (2014) Cancer statistics, 2014. CA Cancer J Clin 64(1): 9-29.

2. Lieberman DA, Rex DK, Winawer SJ, Giardiello FM, Johnson DA, et al. (2012) Guidelines for colonoscopy surveillance after screening and polypectomy: a consensus update by the us multi-societytask Force on Colorectal Cancer. Gastroenterology 143(3): 844-857.

3. Kudo S, Tamura S, Nakajima T, Yamano H, Kusaka H, et al. (1996) Diagnosis of colorectal tumorous lesions by magnifying endoscopy. Gastrointest Endosc 44(1): 8-14.

4. Song LM, Adler DG, Conway JD, Diehl DL, Farraye FA, et al. (2008) Narrow band imaging and multiband imaging. Gastrointest Endosc 67(4): 581589.

5. Gono K, Obi T, Yamaguchi M, Ohyama N, Machida H, et al. (2004) Appearance of enhanced tissue features in narrow-band endoscopic imaging. J Biomed Opt 9(3): 568-577.

6. Kuznetsov K, Lambert R, Rey JF (2006) Narrow-band imaging: potential and limitations. Endoscopy 38(1): 76-81.

7. Kara MA, Ennahachi M, Fockens P, Ten Kate FJ, Bergman JJ (2006) Detection and classification of the mucosal and vascular patterns (mucosal morphology) in Barrett's esophagus by using narrow band imaging. Gastrointest Endosc 64(2): 155-166.

8. Kaise M, Kato M, Urashima M, Arai Y, Kaneyama H, et al. (2009) Magnifying endoscopy combined with narrow-band imaging for differential diagnosis of superficial depressed gastric lesions. Endoscopy 41(4): 310-315.

9. Pennachi CMPS, Moura DTH, Amorim RBP, Guedes HG1, Kumbhari V, et al. (2017) Lugol's iodine chromoendoscopy versus narrow band image enhanced endoscopy forthe detection of esophageal cancer in patients with stenosis secondary tocaustic/corrosive agent ingestion. ArqGastroenterol 54(3): 250-254.

10. Morita FHA, Bernardo WM, Ide E, Rocha RSP, Aquino JCM, et al. (2017) Narrow band imaging versus lugol chromoendoscopy to diagnose squamous cell carcinoma of the esophagus: asystematic review and meta-analysis. BMC Cancer 17(1): 54

11. Repici A, Hassan C, Radaelli F, Occhipinti P, De Angelis C, et al. (2013) Accuracy of narrow-band imaging in predicting colonoscopy surveillance intervals and histology of distal diminutive polyps: results from a multicenter, prospective trial. Gastrointest Endosc 78(1): 106-114.

12. Wallace MB, Crook JE, Coe S, Ussui V, Staggs E, et al. (2014) Accuracy of in vivo colorectal polyp discrimination by using dual-focus high-definition narrow-band imaging colonoscopy. Gastrointest Endosc 80(6): 10721087.

13. Singh R, Jayanna M, Navadgi S, Ruszkiewicz A, Saito Y, et al. (2013) Narrow-band imaging with dual focus magnification in differentiating colorectal neoplasia. Dig Endosc 25(Suppl 2): 16-20.

14. Hewett DG, Kaltenbach T, Sano Y, Tanaka S, Saunders BP, et al. (2012) Validation of a simple classification system for endoscopic diagnosis of small colorectal polyps using narrow-band imaging. Gastroenterology 143(3): 599-607.

15. Togashi K, Osawa H, Koinuma K, Hayashi Y, Miyata T, et al. (2009) A comparison of conventional endoscopy, chromoendoscopy, and the optimal band imaging system for the differentiation of neoplastic and non-neoplastic colonic polyps. Gastrointest Endosc 69(3 Pt 2): 734-741.

16. Parra-Blanco A, Jimenez A, Rembacken B, González N, Nicolás-Pérez D, et al. (2009) Validation of Fujinon intelligent chromoendoscopy with high definition endoscopes in colonoscopy. World J Gastroenterol 15(42): 5266-5273.

17. Pohl J, Lotterer E, Balzer C, Sackmann M, Schmidt KD, et al. (2009) Computed virtual chromoendoscopy versus standard colonoscopy with targeted indigocarmine chromoscopy: a randomized multicentre trial. Gut 58(1): 73-78.

18. Neumann H, Fujishiro M, Wilcox CM, Mönkemüller K (2014) Present and future perspectives of virtual chromoendoscopy with I-Scan and optical enhancement technology. Dig Endosc 26(suppl 1): S43-S51.

19. Akarsu M, Akarsu C (2018) Evaluation of new technologies in gastrointestinal endoscopy. JSLS 22(1).

20. KiesslichR, Sanduleanu S (2011) In: (Eds) I-Scan Mini-Atlas, Hamburg, Pentax, Europe.

21. Hoffman A, Sar F, Goetz M, Tresch A, Mudter J, et al. (2010) High definition colonoscopy combined with i-Scan is superior in the detection of colorectal neoplasias compared with standard video colonoscopy: a prospective randomized controlled trial. Endoscopy 42(10): 827-883.

22. Haito-Chavez Y, Law J K, Kratt T, Arezzo A, Verra M, et al. (2014) International multicenter experience with an over-the-scope clipping device for endoscopic management of GI defects (with video). Gastrointest Endosc 80(4): 610-622.

23. Manta R, Galloro G, Mangiavillano B, Conigliaro R, Pasquale L, et al. (2013) Over-the-scope clip (OTSC) represents an effective endoscopic treatment for acute GI bleeding after failure of conventional techniques. Surg Endosc 27(9): 3162-3164.

24. Weilert F, Binmoeller KF (2016) New endoscopic technologies and procedural advances for endoscopic hemostasis. Clin Gastroenterol Hepatol 14(9): 1234-1244.

25. Irani S, Baron TH, Kozarek RA (2018) Sp605 a solution for the migrating stent: use of the OTSC device to hold fully covered esophageal stents in place. GIE 77(5): AB113. 
26. Wang F, Li Q Zhang X, Jiang G1, Ge X, et al. (2016) Endoscopic radiofrequency ablation for malignant biliary strictures. Exp Ther Med 11(6): 2484-2488.

27. Franzini TA, Moura RN, De Moura EG (2016) Advances in therapeutic cholangioscopy. Gastroenterol Res Pract 7.

28. Phoa K, Rosmolen W, Weusten B, Bisschops R, Schoon EJ, et al. (2017) The costeffectiveness of radiofrequency ablation for Barrett's esophagus with low-grade dysplasia: results from a randomized controlled trial (SURF-trial). Gastrointest Endosc 86(1): 120-129.

29. Phoa KN, Pouw RE, Bisschops R, Pech O, Ragunath K, et al. (2016) Multimodality endoscopic eradication for neoplastic Barrett oesophagus: results of an European multicentre study (EURO-II). Gut 65(4): 555-562.

30. McGorisk T, Krishnan K, Keefer L, Komanduri S (2013) Radiofrequency ablation for refractory gastric antral vascular ectasia (with video). Gastrointest Endosc 78(4): 584-588.

31. Gross SA, Al-Haddad M, Gill KR, Schore AN, Wallace MB (2008) Endoscopicmucosal ablation for the treatment of gastric antral vascular ectasia with the HALO90 system: a pilot study. Gastrointest Endosc 67(2): 324-327.

32. Kallis Y, Phillips N, Steel A, Kaltsidis H4, Vlavianos P, et al. (2015) Analysis of endoscopic radiofrequency ablation of biliary malignant strictures in pancreatic cancer suggests potential survival benefit. Dig Dis Sci 60(11): 3449-3455

33. Holster IL, Van Beusekom HM, Kuipers EJ, Leebeek FW, De Maat MP, et al. (2015) Effects of a hemostatic powder hemospray on coagulation and clot formation. Endoscopy 47(7): 638-645.
34. Haddara S, Jacques J, Lecleire S, Branche J, Leblanc S, et al. (2016) A novel hemostatic powder for upper gastrointestinal bleeding: a multicenter study (the "GRAPHE" registry). Endoscopy 48(12): 1084-1096.

35. Bradley EL, Clements JL, Gonzalez AC (1979) The natural history of pancreatic pseudocysts: a unified concept of management. Am J Surg 137(1): 135-141.

36. Saul A, Luna MAR, Chan C, Uscanga L, Valdovinos AF, et al. (2016) EUSguided drainage of pancreatic pseudocysts offers similar success and complications compared to surgical treatment but with a lower cost. Surg Endosc 30(4): 1459-1465.

37. AlaliA, Mosko J, May G, Teshima C (2017) Endoscopic ultrasound-guided management of pancreatic fluid collections: update and review of the literature. Clin Endosc 50(2): 117-125

38. Walter D, Will U, Sanchez-Yague A, Brenke D, Hampe J, et al. (2015) A novel lumen-apposing metal stent for endoscopic ultrasound-guided drainage of pancreatic fluid collections: a prospective cohort study. Endoscopy 47(1): 63-67.

39. Khan MA, Atiq O, Kubiliun N, Ali B, Kamal F, et al. (2017) Efficacy and safety of endoscopic gallbladder drainage in acute cholecystitis: is it better than percutaneous gallbladder drainage?. Gastrointest Endosc 85(1): 76-87.

40. Kedia P, Sharaiha RZ, Kumta NA, Widmer J, Jamal-Kabani A, et al. (2015) Endoscopic gallbladder drainage compared with percutaneous drainage. Gastrointest Endosc 82(6): 1031-1036.
Creative Commons Attribution 4.0 International License

For possible submissions Click Here

\section{Submit Article}

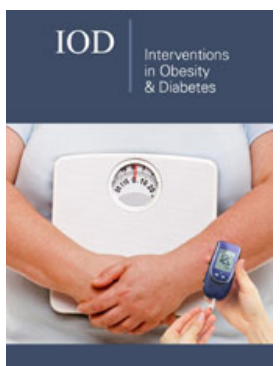

\section{Intervention in Obesity \& Diabetes}

\section{Benefits of Publishing with us}

- High-level peer review and editorial services

- Freely accessible online immediately upon publication

- Authors retain the copyright to their work

- Licensing it under a Creative Commons license

- Visibility through different online platforms 